Check for updates

Cite this: RSC Adv., 2019, 9, 28253

Received 14th July 2019

Accepted 22nd August 2019

DOI: $10.1039 / \mathrm{c} 9 \mathrm{ra05386g}$

rsc.li/rsc-advances

\section{Mesoporous carbon with high content of graphitic nitrogen for selective oxidation of ethylbenzene $\uparrow$}

\author{
Jia Wang, (D) Xiaoli Pan ${ }^{\mathrm{b}}$ and Fuwei Li (D)*a \\ Graphitic-nitrogen doped mesoporous carbon (accounting 85\% in all nitrogen species) was easily \\ synthesized by using acetonitrile as a precursor and SBA-15 as a hard template through a chemical \\ vapour deposition method and exhibited a better catalytic performance than other nitrogen-doped \\ carbon materials for selective oxidation of ethylbenzene.
}

Selective oxidation of hydrocarbons to corresponding high value-added oxygen-containing products (alcohols, aldehydes, ketones and acids, etc.) is one of the most important reactions in organic synthesis and chemical industry., ${ }^{\mathbf{1 , 2}}$ Generally, heterogeneous or homogeneous catalysts, such as transition metals or organometallic centers, are used to efficiently functionalize $\mathrm{C}-\mathrm{H}$ bond..$^{3-7}$ Besides, metal-doped carbon nitrides as catalysts and $\mathrm{N}$-alkoxysulfonyloxaziridines have been used for the activation of $\mathrm{C}-\mathrm{H}$ bonds. ${ }^{\mathbf{8}-10}$ Despite the high efficiency that could be obtained in these processes, the presence of metals or complicated catalytic systems is required for superior performance.

Nanocarbon materials with or without dopants as a metalfree heterogeneous catalysts have been used in many organic reactions, such as dehydrogenation of short-chain alkanes, ${ }^{\mathbf{1 1 , 1 2}}$ hydrogen transfer reductions, ${ }^{\mathbf{1 3 - 1 5}}$ selective oxidation of alcohols, ${ }^{16-19}$ amines, ${ }^{20}$ and arenes, ${ }^{21,22}$ Friedel-Crafts alkylation reactions, ${ }^{23}$ and condensation reactions. ${ }^{\mathbf{2 4 , 2 5}}$ Obviously, in these reactions, especially for oxidation process, the introduction of heteroatoms ( $\mathrm{N}, \mathrm{B}, \mathrm{S}$ etc.) into carbon matrix could enhance its catalytic performance, due to the improvement of electron features. Especially, Ma and co-workers found that layered carbon doped with graphitic-type nitrogen could regulate the electronic structure of the adjacent carbon atoms and facilitated the conversion of ethylbenzene (EB) to acetophenone (AcPO) using TBHP as oxidant. ${ }^{26}$ Apparently, the introduction of nitrogen enhanced the activity of the layered carbon. However, there may be still metal residual because graphene oxide was made by modified Hummers' method. ${ }^{13}$ Recently, N, P, S codoped hollow carbon shells (NPS-HCS) was synthesized and

${ }^{a}$ State Key Laboratory for Oxo Synthesis and Selective Oxidation, Lanzhou Institute of Chemical Physics, Chinese Academy of Sciences, Lanzhou 730000, PR China. E-mail: fuweili@licp.cas.cn

${ }^{b}$ State Key Laboratory of Catalysis, iChEM (Collaborative Innovation Center of Chemistry for Energy Materials), Dalian Institute of Chemical Physics, Chinese Academy of Sciences, Dalian 116023, China

$\dagger$ Electronic supplementary information (ESI) available: Materials preparation, characterization methods, and additional figures, tables and references. See DOI: $10.1039 / \mathrm{c} 9 \mathrm{ra05386g}$ exhibited a good catalytic performance in the oxidation of EB. ${ }^{27}$ In our previous work, ${ }^{28}$ nitrogen-containing ordered mesoporous carbon (NOMC) which was synthesized by using $m$ aminophenol as a carbon and nitrogen co-precursor via a coassembly process with F127 in aqueous phase could effectively convert EB to AcPO. It was worth noting that during the synthesis process no metal was induced. Therefore, it could exclude the effects of the metal impurities in nanocarbon materials on its performance for the EB oxidation. However, it is necessary to further improve its catalytic performance by regulating its surface chemical property because there exist varieties of nitrogen species in NOMC.

Herein, we selected SBA-15 as a hard template and acetonitrile as precursor and directly synthesized graphitic-N doped mesoporous carbon (GNMC) in order to introduce high level graphitic nitrogen and avoid any metals. These GNMC with high graphitic- $\mathrm{N}$ content exhibited a better catalytic performance than other nitrogen-doped carbon materials for the selective oxidation of EB.

SEM results shown in Fig. S1† indicate that all the MC and GNMC have similar wormlike rod structure with coarse surface, which derives from the hard template (SBA-15). Obvious diffraction peak of stacked graphitic sheet is observed in XRD patterns (Fig. S2 $\dagger$ ), and the (002) peak intensity of GNMC is higher than that of MC, suggesting higher graphitic extent. Besides, the increase of $2 \theta$ ((002) peak) from $24.7^{\circ}$ for MC to $25.9^{\circ}$ for GNMC, indicating that the incorporation of nitrogen makes a decrease of interplanar crystal spacing of (002). Typical $\mathrm{N}_{2}$ adsorption-desorption isotherms and corresponding pore size distributions of the GNMC are shown in Fig. 1A and B. A clear hysteresis loop in the $P / P_{\mathrm{o}}>0.4$ is observed for GNMC, suggesting an existence of mesostructure. According to the Brunauer-Emmett-Teller (BET) method, the specific BET surface area of GNMC is calculated to be $371 \mathrm{~m}^{2} \mathrm{~g}^{-1}$. The total pore volume is $0.47 \mathrm{~cm}^{3} \mathrm{~g}^{-1}$. The pore size calculated from the adsorption branch (Fig. 1B) using the Barrett-Joyner-Halenda (BJH) model is $\sim 4.1 \mathrm{~nm}$. However, as for $\mathrm{MC}$ (mesoporous carbon without doping nitrogen, using ethanol as precursor, see synthesis process in ESI $\dagger$ ), weak hysteresis loop is observed 

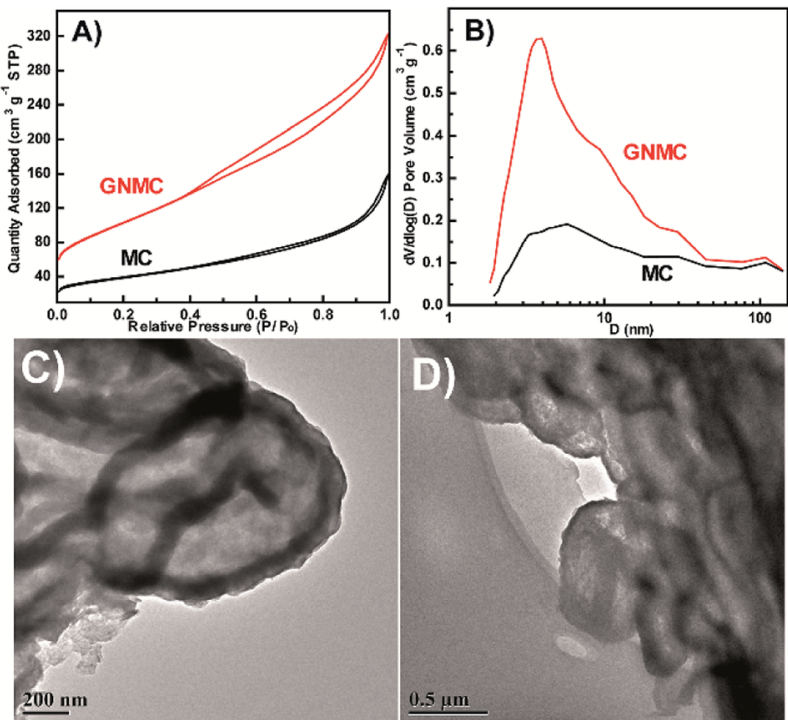

Fig. $1 \mathrm{~N}_{2}$ adsorption-desorption isotherms of $M C$ and GNMC (A) and corresponding pore size distributions (B). TEM images of $M C$ (C) and GNMC (D)

and its pore size distributions is wider than that of GNMC. Its specific surface area is only about $137 \mathrm{~m}^{2} \mathrm{~g}^{-1}$ and the total pore volume is $0.22 \mathrm{~cm}^{3} \mathrm{~g}^{-1}$. The obvious mesoporous structure of MC and GNMC is also evidenced by transmission electron microscopy (TEM) as shown in Fig. 1C and D, respectively. However, the ordered mesoporous structure is not maintained after removing SBA-15, which may be due to the high steam concentration of ethanol or acetonitrile on the surface of SAB-15 once the furnace was heated at $90{ }^{\circ} \mathrm{C}$, resulting in the diffusion difficulty of ethanol or acetonitrile steam into pore channel of SBA-15 (see synthesis process in ESI $\dagger$ ). Unlike this synthesis process, another manner to bring in liquid precursor by a flow of nitrogen saturated with acetonitrile vapour at room temperature could obtain ordered mesostructure. ${ }^{29}$ The evident graphitic order with bent layer planes in both these materials is observed in high-resolution transmission electron microscopy (HRTEM) shown in Fig. S3A and B, $\dagger$ indicating the formation of pore walls with graphitic character.

In order to understand these samples' composition, element analysis (EA) was conducted (Table $\mathrm{S} 1 \dagger$ ). EA reveals that the $\mathrm{N}$ content of MC is very low $(0.111 \mathrm{wt} \%$, close to the detection limit of the instrument), while $7.3 \mathrm{wt} \%$ of $\mathrm{N}$ content is obtained for GNMC. The composition of $\mathrm{C} / \mathrm{N} / \mathrm{H} / \mathrm{O}$ is 100/0.1/3.7/0.1 and 100/ 8.6/3.4/6.9 for MC and GNMC, respectively, indicating that the framework is carbon due to the high synthesis temperature.

XPS spectra were further employed to detect the surface chemistry properties of these samples, especially the nature and coordination of the nitrogen atoms, due to the bulk elemental composition shown by EA results. Fig. $\mathrm{S} 4 \uparrow$ shows the spectra of $\mathrm{MC}$, GNMC and GNMC/SBA-15. The obvious $\mathrm{N}$ signal is observed in the XPS spectra of GNMC and GNMC/SBA-15 indicating that nitrogen could be introduced into carbon using acetonitrile as precursor. Moreover, GNMC and GNMC/SBA-15 contain the similar nitrogen content, 3.1 at $\%$ for GNMC/SBA-
15 and 3.5 at\% for GNMC (Table 1), suggesting that $\mathrm{N}$ content could be hardly affected by removing SBA-15. N 1s spectra in Fig. 2A shows that the main nitrogen species in GNMC and GNMC/SBA-15 could be attributed to graphitic nitrogen, which accounts for $85 \%$ in all nitrogen species for GNMC (Table S2 $\dagger$ ). The similar method using acetonitrile as precursor has also been reported to synthesize nitrogen-doped graphene, ${ }^{30}$ nitrogen-doped carbon nanotubes ${ }^{31}$ and nitrogen-doped ordered mesoporous carbon. ${ }^{29}$ ATR-IR spectroscopy was also conducted to detect the surface chemical-bonding state (Fig. S5 $\dagger$ ). However, due to the black appearance (synthesized at high temperature $950{ }^{\circ} \mathrm{C}$ ), no obvious peaks are observed for these two samples. Besides, ${ }^{13} \mathrm{C}$ NMR spectra and UV-vis DRS for MC and GNMC were also conducted to understand the chemical property (Fig. S6 and $\mathrm{S} 7 \dagger$ ). Unfortunately, all the samples exhibit similar ${ }^{13} \mathrm{C}$ NMR spectra, and no obvious peaks are observed for their UV-vis DRS, which may be due to their good conductivity.

In order to understand the carbon content and oxidation stability, the three samples (GNMC, GNMC/SBA-15 and MC) was investigated by TG technique under $10 \% \mathrm{O}_{2} / \mathrm{Ar}$ atmosphere. As shown in Fig. 2B, about 37 wt $\%$ carbon on SBA-15 is obtained after CVD process. Besides, the removal of SBA-15 resulted in the decrease of oxidation stability. GNMC could be oxidized more easily than MC, suggesting that the introduction of nitrogen significantly promoted the oxidation of carbon. ${ }^{32}$

The high specific surface area, open mesoporous system and onefold graphitic nitrogen species for GNMC supported by above results encourage us to test the synthesized GNMC in selective liquid-phase oxidation of $\mathrm{EB}$, in which the introduction of $\mathrm{N}$ into carbon materials plays a very important role. In our experiments, the main products of EB oxidation using tertbutyl hydroperoxide (THBP) as oxidant are shown in Table S3. $\dagger$ They are acetophenone (AcPO), 1-phenyl-ethylalcohol (PEA), benzaldehyde (BA) and benzoic acid (BzA). The effects of reaction temperature, the molar ratio of $\mathrm{EB} / \mathrm{TBHP}$, reaction time on

Table 1 Catalytic activity of different carbon materials for the liquid phase oxidation of $\mathrm{EB}^{a}$ and their textural property ${ }^{b}$ and chemical composition $^{c}$

\begin{tabular}{|c|c|c|c|c|c|c|c|c|}
\hline & \multirow[b]{2}{*}{ Cat. } & \multirow[b]{2}{*}{$S_{\mathrm{BET}}$} & \multicolumn{3}{|l|}{ XPS } & \multirow[b]{2}{*}{ Con. ${ }^{d}$} & \multirow[b]{2}{*}{ Sel. $^{e}$} & \multirow[b]{2}{*}{ Yield rate ${ }^{g}$} \\
\hline & & & C $1 \mathrm{~s}$ & $\mathrm{~N}$ 1s & O 1s & & & \\
\hline 1 & Blank & - & - & - & - & 13.8 & 14.1 & - \\
\hline 2 & MC & 137 & 90.9 & - & 9.1 & 20.2 & 18.5 & 22.6 \\
\hline 3 & CMK-3 & 1153 & 95.4 & 0.2 & 4.3 & 28.5 & 35.3 & 122.1 \\
\hline 4 & GNMC & 371 & 87.5 & 3.5 & 8.9 & 79.5 & 97.6 & 932.6 \\
\hline 5 & MCN & 558 & 82.6 & 12.6 & 4.8 & 31.9 & 40.2 & 154.1 \\
\hline 6 & NOLC & 406 & 95.7 & 1.9 & 2.4 & 41.3 & 45.4 & 229.7 \\
\hline 7 & NCNT & 87.8 & 94.8 & 1.8 & 2.6 & 56.9 & 94.2 & 669.9 \\
\hline 8 & GNMC/SBA-15 & - & 86.1 & 3.1 & 10.8 & 21.9 & 12.9 & 34.9 \\
\hline $9^{f}$ & GNMC/SBA-15 & - & 86.1 & 3.1 & 10.8 & 30.5 & 25.9 & 36.6 \\
\hline
\end{tabular}

${ }^{a}$ Reaction condition: $2 \mathrm{~mL}$ acetonitrile, $1.5 \mathrm{mmol} \mathrm{EB}, 10 \mathrm{mg}$ catalyst, $\mathrm{EB} / \mathrm{TBHP}=1 / 3,80{ }^{\circ} \mathrm{C}, 12 \mathrm{~h} .{ }^{b}$ Calculated according to BET method (unit: $\mathrm{m}^{2} \mathrm{~g}^{-1}$ ) from $\mathrm{N}_{2}$ adsorption-desorption data. ${ }^{c}$ Measured from XPS spectra (unit: at\%). ${ }^{d}$ EB conversion (unit: \%). ${ }^{e}$ AcPO selectivity (unit: \%). ${ }^{f} 27 \mathrm{mg}$ catalyst. ${ }^{g}$ Yield rate of AcPO (unit: $\mathrm{mmol} \mathrm{g}^{-1} \mathrm{~h}^{-1}$ ). 
A)

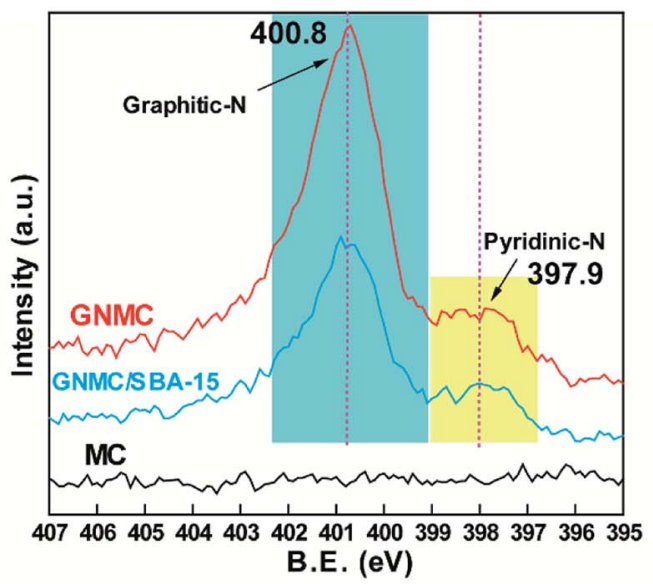

B)

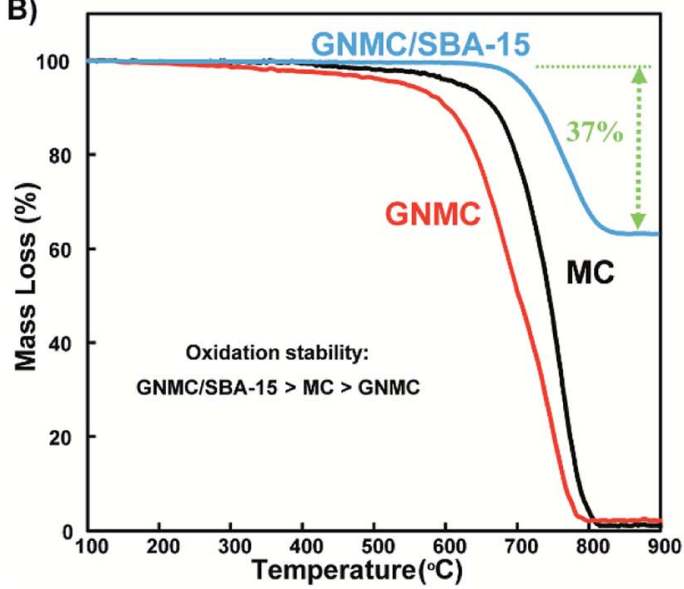

Fig. 2 (A) N 1s spectra of MC, GNMC and GNMC/SBA-15. (B) TPO curves of GNMC/SBA-15, MC and GNMC.

the catalytic performances of GNMC were systematically investigated in the selective oxidation of EB. The blank test indicates that there is a low reaction activity due to the EB autoxidation ${ }^{33}$ (Table 1, entry 1 ).

Fig. 3A shows the effect of reaction temperature on the catalytic activity of GNMC for the oxidation of EB. The conversion of EB obviously increases from $26.4 \%$ to $79.5 \%$ with the increase of temperature from $30{ }^{\circ} \mathrm{C}$ to $80{ }^{\circ} \mathrm{C}$, and the selectivity for AcPO increases from $34.2 \%$ to $97.6 \%$. However, when the temperature increases to $90{ }^{\circ} \mathrm{C}$, EB conversion slightly increases to $80.9 \%$ and AcPO selectivity further increases to $99.1 \%$. This phenomenon is probably ascribed to the increasing effective conversion of THBP to active oxygen groups when raising temperature. As shown in Table $\mathrm{S} 3, \dagger \mathrm{BzA}$ is the main side product at $30{ }^{\circ} \mathrm{C}$, which significantly decreases from $52.8 \%$ to $2.9 \%$ with the increase of temperature from $30{ }^{\circ} \mathrm{C}$ to $90{ }^{\circ} \mathrm{C}$, and the selectivity for the other two side products also decreases with the increase of temperature. Therefore, these results show that the reaction temperature is a key factor for the conversion of $\mathrm{EB}$ to $\mathrm{AcPO}$, and the appropriate temperature is $80{ }^{\circ} \mathrm{C}$. Besides, the conversion of TBHP also increase with the enhancement of reaction temperature (Fig. 3A). However, the consumption rate of EB does not linearly increase with the
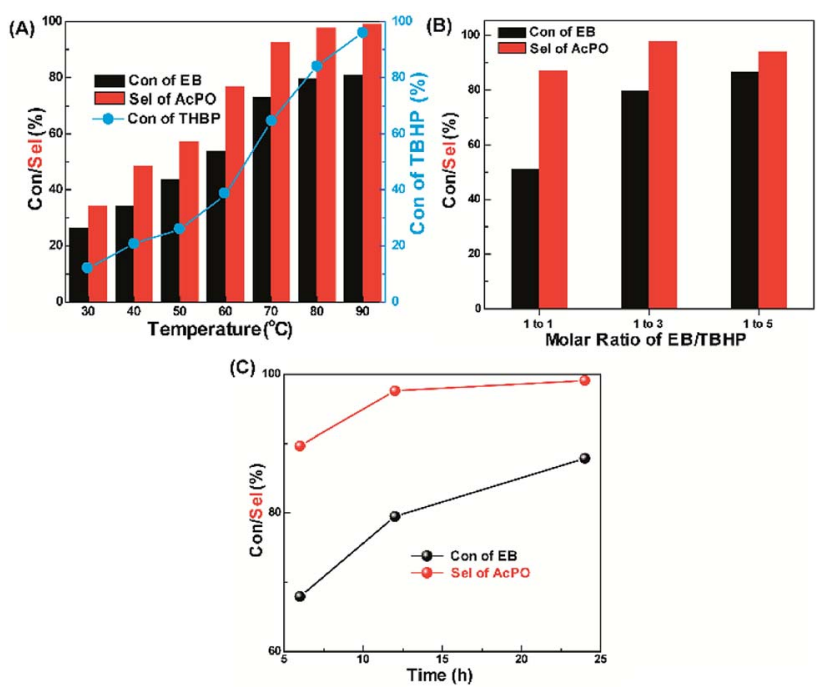

Fig. 3 (A) The effect of reaction temperature on the catalytic oxidation of EB with TBHP as oxidant in the presence of GNMC. Reaction conditions: $1.5 \mathrm{mmol} \mathrm{EB}, 2 \mathrm{~mL} \mathrm{CH}{ }_{3} \mathrm{CN}, 10 \mathrm{mg}$ GNMC, $12 \mathrm{~h}$, molar ratio of $E B / T B H P=1 / 3$. (B) The effect of molar ratio of $E B / T B H P$ on the catalytic oxidation of EB with TBHP as oxidant in the presence of GNMC. Reaction conditions: $1.5 \mathrm{mmol} E B, 2 \mathrm{~mL} \mathrm{CH} 3 \mathrm{CN}, 10 \mathrm{mg}$ GNMC, $12 \mathrm{~h}, 80^{\circ} \mathrm{C}$. (C) The effect of reaction time on the catalytic oxidation of EB with TBHP as oxidant in the presence of GNMC. Reaction condi-

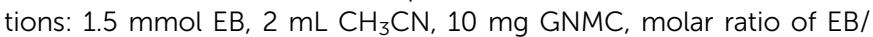
$\mathrm{TBHP}=1 / 3,80^{\circ} \mathrm{C}$

increase of the TBHP consumption rate as shown in Fig. S8. $\dagger$ The values of carbon balance of the reaction on GNMC catalyst under different reaction temperature are also shown Table S3. $\dagger$ We could observe that all of the carbon balance value is close to $98 \pm 5 \%$, suggesting a good mass balance and few unknown products.

Fig. 3B shows the effect of molar ratio of $\mathrm{EB} / \mathrm{TBHP}$ on the catalytic performance of GNMC for EB oxidation. With the decrease of EB/TBHP ratio from $1 / 1$ to $1 / 3$, EB conversion increases from $51.1 \%$ to $79.5 \%$ accompanied with the increase of AcPO selectivity from $86.8 \%$ to $97.6 \%$. Nevertheless, further decrease of EB/TBHP ratio to 1/5, the AcPO selectivity slightly decreased with the slight increase of EB conversion. Therefore, the appropriate molar ratio of $\mathrm{EB} / \mathrm{TBHP}$ is $1 / 3$. With the increase of TBHP concentration, the amount of active oxygen groups also increases, resulting in the increase of EB conversion. However, high concentrated active oxygen groups might produce the sideproducts, bringing about the decrease of AcPO selectivity. The effect of reaction time on the catalytic activity of GNMC for EB oxidation is shown in Fig. 3C. EB conversion and AcPO selectivity initially increases sharply in the period 6-12 h. And with further increase of reaction time, AcPO selectivity had no obvious increase and the conversion for EB gradually increase. So, here $12 \mathrm{~h}$ reaction period is chosen because of too long period of $24 \mathrm{~h}$.

The results of various carbon catalysts for selective liquidphase oxidation of EB are summarized in Table 1. MC exhibits higher catalytic performance than that observed in the blank test, indicating that the carbon material itself could 
convert EB to AcPO. However, AcPO selectivity on MC is only $35.3 \%$. CMK-3 is an ordered mesoporous carbon which possesses high specific surface area and shows a little better performance than that of MC (entry 3). This result suggests that the catalytic activity is not directly related to the specific surface area of the catalysts, that is to say specific surface are is not a key factor on catalytic activity of carbon material. There is an obvious increase of catalytic performance using GNMC as a catalyst (entry 4), on which the selectivity for AcPO reaches to $97.6 \%$ at EB conversion of $79.5 \%$. MCN which is synthesized according the reported method, ${ }^{34}$ is a mesoporous carbon nitrides and contains 12.6 at\% nitrogen content (entry 5). However, its catalytic activity $(31.9 \%$ of EB conversion and $40.2 \%$ of AcPO selectivity, entry 5 ) is far lower than that of GNMC, although the nitrogen content of GNMC (3.5 at\%, entry 4 ) is much lower than that of MCN. Besides, other nitrogendoped nanocarbon materials were also synthesized and tested for EB oxidation. Nitrogen-doped onion-like carbon (NOLC) synthesized according to literature ${ }^{35}$ only exhibits $41.3 \%$ of EB conversion and $45.4 \%$ of AcPO selectivity (entry 6), although it shows superior catalytic performance for the expoxidation of styrene. $^{35}$ Nitrogen-doped carbon nanotubes (NCNT), which shows a good catalytic activity in some oxidation reactions, ${ }^{36-38}$ was synthesized at $900{ }^{\circ} \mathrm{C}$ using imidazole as a precursor performs $56.9 \%$ of EB conversion and $94.2 \%$ of AcPO selectivity (entry 7). As shown in Fig. 2A, the main species of nitrogen in GNMC is graphitic nitrogen $(400.8 \mathrm{eV}) \cdot{ }^{39,40}$ However the main nitrogen for MCN is not graphitic nitrogen but nitrogen trigonally bonded to all $\mathrm{sp}^{2}$ carbon atoms $\mathrm{s}^{\mathbf{3 4 , 4 1 , 4 2}}$ as shown in Fig. S9. $\dagger$ The deconvolution analysis results of $\mathrm{N}$ 1s for GNMC, NOLC and NCNT are shown in Table $\mathrm{S} 1, \dagger$ which indicates that NOLC and NCNT contains various nitrogen species with very low graphitic nitrogen content. Consequently, these results suggest that the introduction of nitrogen, especially for graphitic nitrogen, plays a very important role in promoting the conversion of EB to AcPO, which is in agreement with a previous report. ${ }^{26}$ Besides, as shown in Table S3, $\dagger$ except CMK-3, MCN and NOLC catalysts, the carbon balance (CB) of other catalysts and blank test is close to $95 \pm 4 \%$, indicating fewer unknown products for MC, GNMC and NCNT catalysts.

In the end, the catalytic performance of GNMC and GNMC/ SBA-15 was compared as shown in Table 1 . Using the same catalyst mass $(10 \mathrm{mg})$, GNMC/SBA-15 performs more inferior activity (entry 8). Besides, increasing the GNMC/SBA-15 mass to $27 \mathrm{mg}$ (the carbon content is about $10 \mathrm{mg}$ calculated from TPO result), the catalytic performance of GNMC/SBA-15 is still poor (entry 9). These results show the decreased accessibility of the GNMC/SBA-15 surface caused by the block of SBA-15.

In summary, using acetonitrile as a carbon and nitrogen precursor, high level of graphitic-nitrogen doped mesoporous carbon without introduction of any metals has been synthesized via CVD method using SBA-15 as a template. Our results show that the ratio of graphitic-nitrogen accounts for $85 \%$ in all nitrogen species for GNMC, which exhibits a good catalytic activity of EB oxidation and AcPO selectivity. The results indicates that although the introduction of nitrogen is necessary for high EB conversion efficiency, the most important factor is to draw into adequate nitrogen species (for example, graphitic nitrogen is a key for the oxidation of EB).

\section{Conflicts of interest}

There are no conflicts to declare.

\section{Acknowledgements}

The authors are grateful for the supports from National Key R\&D Program of China (2018YFB1501600), the National Natural Science Foundation of China (21802149, 21773271, 21522309), the China Postdoctoral Science Foundation (2017M623280), the Cooperation Foundation of Dalian National Laboratory for Clean Energy (DNL180303), the Natural Science Foundation of Jiangsu Province (BK20160395), and the Chinese Academy of Sciences.

\section{Notes and references}

1 A. N. Campbell and S. S. Stahl, Acc. Chem. Res., 2011, 45, 851. 2 L. Gómez-Hortigüela, F. Corà and C. R. A. Catlow, ACS Catal., 2011, 1, 1475.

3 J. A. Labinger and J. E. Bercaw, Nature, 2002, 417, 507.

4 X. B. Fu, H. Yu, F. Peng, H. J. Wang and Y. Qian, Appl. Catal., A, 2007, 321, 190.

5 X. H. Li, X. C. Wang and M. Antonietti, ACS Catal., 2012, 2, 2082.

6 G. Wu, Y. Gao, F. W. Ma, B. H. Zheng, L. G. Liu, H. Y. Sun and W. Wu, Chem. Eng. J., 2015, 271, 14.

7 L. Yang and H. Huang, Chem. Rev., 2015, 115, 3468.

8 B. H. Brodsky and J. D. Bois, J. Am. Chem. Soc., 2005, 127, 15391.

9 Y. Wang, J. Zhang, X. Wang, M. Antonietti and H. Li, Angew. Chem., Int. Ed., 2010, 49, 3356.

10 D. X. Yang, T. Jiang, T. B. Wu, P. Zhang, H. L. Han and B. X. Han, Catal. Sci. Technol., 2016, 6, 193.

11 J. Zhang, X. Liu, R. Blume, A. H. Zhang, R. Schlogl and D. S. Su, Science, 2008, 322, 73.

12 R. Huang, J. Y. Xu, J. Wang, X. Y. Sun, W. Qi, C. H. Liang and D. S. Su, Carbon, 2016, 96, 631.

13 Y. J. Gao, D. Ma, C. L. Wang, J. Guan and X. H. Bao, Chem. Commun., 2011, 47, 2432.

14 S. C. Wu, G. D. Wen, B. W. Zhong, B. S. Zhang, X. M. Gu, N. Wang and D. S. Su, Appl. Catal., A, 2014, 35, 914.

15 H. M. Yang, X. J. Cui, X. C. Dai, Y. Q. Deng and F. Shi, Nat. Commun., 2015, 6, 6478.

16 Y. B. Kuang, N. M. Islam, Y. Nabae, T. Hayakawa and M. A. Kakimoto, Angew. Chem., Int. Ed., 2010, 49, 436.

17 J. L. Long, X. Q. Xie, J. Xu, Q. Gu, L. M. Chen and X. X. Wang, ACS Catal., 2012, 2, 622.

18 J. Luo, F. Peng, H. Yu and H. H. Wang, Chem. Eng. J., 2012, 204, 98.

19 Y. M. Lin and D. S. Su, ACS Nano, 2014, 8, 7823.

20 B. Chen, L. Y. Wang, W. Dai, S. S. Shang, Y. Lv and S. Gao, ACS Catal., 2015, 5, 2788. 
21 H. Yu, F. Peng, J. Tan, X. W. Hu, H. J. Wang, J. Yang and W. X. Zheng, Angew. Chem., Int. Ed., 2011, 50, 3978.

22 G. D. Wen, S. C. Wu, B. Li, C. L. Dai and D. S. Su, Angew. Chem., Int. Ed., 2015, 54, 4105.

23 F. Hu, M. Patel, F. Luo, C. Flach, R. Mendelsohn, E. Garfunkel, H. X. He and M. Szostak, J. Am. Chem. Soc., 2015, 137, 14473.

24 J. P. Tessonnier, A. Villa, O. Majoulet, D. S. Su and R. Schlogl, Angew. Chem., Int. Ed., 2009, 48, 6543.

25 S. van Dommele, K. P. de Jong and J. H. Bitter, Top. Catal., 2009, 52, 1575.

26 Y. J. Gao, G. Hu, J. Zhong, Z. J. Shi, Y. S. Zhu, D. S. Su, J. G. Wang, X. H. Bao and D. Ma, Angew. Chem., Int. Ed., 2013, 52, 2109.

27 S. L. Yang, L. Peng, P. P. Huang, X. S. Wang, Y. B. Sun, C. Y. Cao and W. G. Song, Angew. Chem., Int. Ed., 2016, 55, 4016.

28 J. Wang, H. Y. Liu, X. M. Gu, H. H. Wang and D. S. Su, Chem. Commun., 2014, 50, 9182.

29 Y. D. Xia and R. Mokaya, Adv. Mater., 2004, 16, 1553.

30 P. Tang, Y. J. Gao, J. H. Yang, W. J. Li, H. B. Zhao and D. Ma, Appl. Catal., A, 2014, 35, 922.

31 P. H. Matter, E. Wang and U. S. Ozkan, J. Catal., 2006, 243, 395.
32 J. Wang, R. Huang, Y. J. Zhang, J. Y. Diao, J. Y. Zhang, H. Y. Liu and D. S. Su, Carbon, 2017, 111, 519.

33 I. Hermans, J. Peeters and P. A. Jacobs, J. Org. Chem., 2007, $72,3057$.

34 A. Vinu, Adv. Funct. Mater., 2008, 18, 816.

35 Y. M. Lin, X. L. Pan, W. Qi, B. S. Zhang and D. S. Su, J. Mater. Chem. A, 2014, 2, 12475.

36 K. Chizari, A. Deneuve, O. Ersen, I. Florea, Y. Liu, D. Edouard, I. Janowska, D. Begin and C. Pham-Huu, ChemSusChem, 2012, 5, 102.

37 Y. H. Cao, H. Yu, F. Peng and H. J. Wang, ACS Catal., 2014, 4, 1617.

38 B. S. Zhong, B. S. Zhang, H. Y. Liu and D. S. Su, Catal. Sci. Technol., 2017, 7, 1279.

39 S. Kundu, W. Xia, W. Busser, M. Becker, D. A. Schmidt, M. Havenith and M. Muhler, Phys. Chem. Chem. Phys., 2010, 12, 4351.

40 Y. H. Cao, H. Yu, J. Tan, F. Peng, H. J. Wang, J. Li, W. X. Zheng and N. B. Wong, Carbon, 2013, 57, 433.

41 A. Vinu, K. Ariga, T. Mori, T. Nakanishi, S. Hishita, D. Golberg and Y. Bando, Adv. Mater., 2005, 17, 1648.

42 A. Vinu, P. Srinivasu, D. P. Sawant, T. Mori, K. Ariga, J. S. Chang, S. H. Jhung, V. V. Balasubramanian and Y. K. Hwang, Chem. Mater., 2007, 19, 4367. 